\title{
Microwave-Induced Interfacial Nanobubbles
}

\author{
Lei Wang, ${ }^{\dagger}$ Xiaojun Miao, ${ }^{\dagger}$ and Gang Pan ${ }^{*},+$, \\ ${ }^{\dagger}$ Research Center for Eco-Environmental Sciences, Chinese Academy of Sciences, Beijing 100085, China \\ ${ }^{\ddagger}$ School of Animal, Rural and Environmental Sciences, Nottingham Trent University, Brackenhurst Campus, Southwell NG25 0QF, \\ United Kingdom
}

\section{Supporting Information}

ABSTRACT: A new method for generating nanobubbles via microwave irradiation was verified and quantified. AFM measurement showed that nanobubbles with diameters ranging from 200 to $600 \mathrm{~nm}$ were generated at a water-HOPG surface by applying microwave radiation to aqueous solutions with 9.0-30.0 $\mathrm{mg} / \mathrm{L}$ dissolved oxygen. Graphite displays strong microwave absorption and transmits high thermal energy to the surface. Because of the high dielectric constant $\left(20^{\circ} \mathrm{C}, 80 \mathrm{~F} / \mathrm{m}\right)$ and dielectric loss factor, water molecules have a strong ability to absorb microwave radiation. The thermal and nonthermal effects of microwave radiation made contributions to decreasing the gas solubility, thus facilitating nanobubble nucleation. The yield of nanobubbles increased about 10-fold when the irradiation time increased from 60 to $120 \mathrm{~s}$ at $200 \mathrm{~W}$ of microwave radiation. The nanobubble density increased from

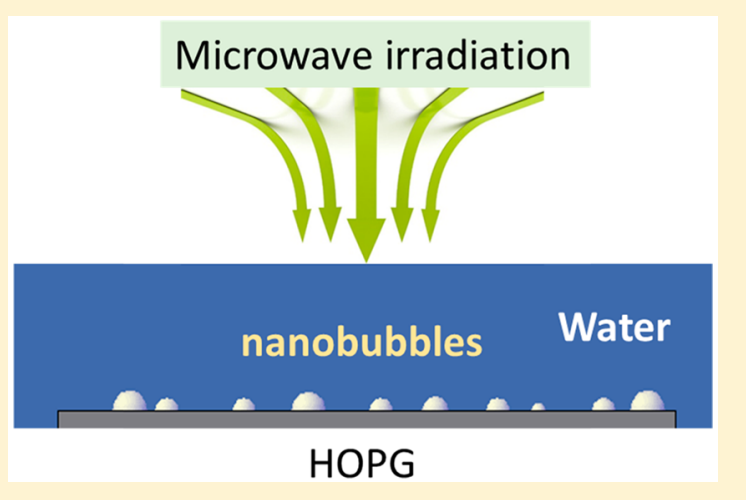
0.8 to $15 \mu \mathrm{m}^{-2}$ by improving the working power from 200 to $600 \mathrm{~W}$. An apparent improvement in nanobubbles yield was obtained between 300 and $400 \mathrm{~W}$, and the resulting temperature was $34-52^{\circ} \mathrm{C}$. When the initial dissolved oxygen increased from 11.3 to $30.0 \mathrm{mg} / \mathrm{L}$, the density of nanobubbles increased from 1.2 to $13 \mu \mathrm{m}^{-2}$. The generation of nanobubbles could be well controlled by adjusting the gas concentration, microwave power, or irradiation time. The method may be valuable in preparing surface nanobubbles quickly and conveniently for various applications, such as catalysis, hypoxia/anoxia remediation, and templates for preparing nanoscale materials.

\section{INTRODUCTION}

Surface nanobubbles are gaseous domains that are typically tens to hundreds of nanometers in radius and 10-100 $\mathrm{nm}$ high. Nanobubbles were first reported by Parker et al. ${ }^{1}$ to explain the effect of the hydrophobic long-range force. In 2000, two research groups reported the first images of nanobubbles on various hydrophobic surfaces in water by AFM, which demonstrated the existence of nanobubbles directly, ${ }^{2,3}$ and this is a significant milestone in nanobubble study. Since then, nanobubbles have attracted increasing attention in various fields, including nanofluidics, ${ }^{4}$ nanomedicine, ${ }^{5,6}$ nanochemistry, ${ }^{7,8}$ and environmental remediation. ${ }^{9-12}$ Investigations have focused on unraveling the mystery behind nanobubble nucleation $^{13-17}$ and the nanobubble stability mechanism including the contamination layer and contact line pinning, ${ }^{18,19}$ quantifying bubble dynamics as a function of different parameters, ${ }^{20-24}$ and developing potential applications in lubrication, ${ }^{25}$ cleaning, ${ }^{26-28}$ mineral flotation, ${ }^{29}$ and the synthesis of highly porous metallic surfaces. ${ }^{30}$ To fully exploit these possibilities, there is the need to prepare various types of gas nanobubbles by simple methods, which can be used to generate nanobubbles in a controlled way.

Research advances in various physical aspects of surface nanobubbles in the past decade include methods of nanobubble generation based on solvent exchange, ${ }^{20,31-33}$ temperature gradients, $^{21,34}$ the plasmonic effect, ${ }^{35}$ and water electroly- sis. ${ }^{36-40}$ Alcohol-water exchange is proven to be an effective method that can generate a large number of air nanobubbles with high repeatability. ${ }^{16,41,42}$ Its efficiency may be attributed to the transient and local gas supersaturation close to the surface when the alcohol, having a high gas solubility, is replaced with water having a lower gas solubility. This local supersaturation presumably triggers the nucleation of small gaseous domains, the nanobubbles. However, the exchange of organic solvents with water has some limitations. It needs large amounts of organic solvents, a fast exchange process, and a stable surface resistant to organic solvents; meanwhile, organic solvents are more likely to introduce contamination into the system and make the analysis complicated. Methods without solvent exchange to nucleate nanobubbles are required for nanobubble research. The generation of plasmonic nanobubbles has drawn attention in the past few years. ${ }^{43,44}$ The irradiation of gold nanoparticles (AuNPs) with nanosecond laser pulses, at a wavelength that matches their plasmon resonance, is an approach commonly used to generate vapor nanobubbles in both water and biological media. This method applies only to

Special Issue: Nanobubbles

Received: April 28, 2016

Revised: $\quad$ May 27, 2016

Published: May 28, 2016 
certain plasmonic nanoparticles and presents a promising diagnostic and therapeutic avenue for various pathologies. 45,46 In recent years, the electrochemical method has been employed to produce nanobubbles on the surface of an electrode. Zhang et al. ${ }^{36}$ and Chen et al. ${ }^{47}$ confirmed that the electrolysis of water induced the formation of hydrogen nanobubbles on highly oriented pyrolytic graphite (HOPG) surfaces or Pt electrodes. Oxygen nanobubbles were determined simultaneously as a byproduct of obtaining hydrogen gas by water electrolysis. ${ }^{48}$ However, the yield of oxygen nanobubble was much lower than that of hydrogen nanobubbles. ${ }^{37}$ More recently, Chen et al. ${ }^{49}$ reported the generation of $\mathrm{N}_{2}$ nanobubbles at $\mathrm{Pt}$ nanoelectrode by the irreversible electrooxidation of hydrazine. However, nanobubble generation by electrolysis is restricted by the type of electrolyte. For now, only water with or without acid and hydrazine have been used as electrolytes. The system temperature proved to be an important factor in the formation of nanobubbles; however, there is the need to advance this method with high efficiency and low energy cost.

Microwave irradiation has pronounced thermal effects. The microwave working principle is based on a water molecule's fast shear flow and molecular friction. ${ }^{50}$ Water molecules can rotate in time with an electric field frequency of $2.45 \mathrm{GHz}$ in liquids. Because of this process, internal friction takes place in the polar medium, which leads to direct heating of the mixture. Graphite has a strong microwave absorption ability because of its low resistance, being able to transmit high thermal energy to the surface, resulting in a dramatic temperature increase on the surface. ${ }^{51-53}$ The hot substrate may provide possibilities for interfacial nanobubble formation in an aqueous solution. Microwave irradiation also has a nonthermal effect. ${ }^{54}$ So far, there are no previous studies on the use of microwave irradiation for nanobubble generation.

Here, we propose to use microwave irradiation to generate interfacial nanobubbles. Oxygen was used as the gas source, and nanobubbles were measured by AFM on an HOPG surface. Influential factors in the formation process such as dissolved oxygen concentration, microwave power, and irradiation time were studied. The objective of the study is to develop a convenient and efficient method for the controlled formation of nanobubbles.

\section{EXPERIMENTAL SECTION}

2.1. Chemicals and Materials. Highly oriented pyrolytic graphite (HOPG) $(1.2 \mathrm{~cm} \times 1.2 \mathrm{~cm}$, Bruker) was used as the substrate. HOPG was freshly cleaved before each experiment by peeling off the outermost layers with Scotch tape.

Water with a conductivity of $18.2 \mathrm{M} \Omega \mathrm{cm}$ at $\mathrm{pH} 7.0$ was obtained from a Milli-Q system (Millipore Corp., Boston, MA). All glass containers for the liquid and tweezers were cleaned with acetone and ethanol, respectively, and then rinsed with water. High-purity oxygen (99.995\%) was used as the gas source for preparing nanobubbles. Experiments were carried out under ambient laboratory conditions.

2.2. Formation of Nanobubbles by Microwave Irradiation. Microwave irradiation was used to prepare interfacial nanobubbles. The water was first degassed by keeping it for $1 \mathrm{~h}$ under a reduced pressure of $30 \mathrm{mbar}$. Then pure oxygen was used to aerate degassed ultrapure water at a flow rate of $160 \mathrm{~mL} / \mathrm{min}$. A dissolved oxygen meter (JPSJ605, Shanghai REX Instrument Factory) was used to detect the concentration of dissolved oxygen (DO). To obtain in situ nanobubble images, freshly cleaved HOPG was fixed on an iron stub with tape and placed into the obtained $50 \mathrm{~mL}$ of solution before the microwave treatment (OTG Motor Co. Ltd.) was started. A schematic diagram of nanobubble generation is shown in Figure 1. After this process, HOPG covered with microwave-treated water was carefully and quickly transferred to the liquid cells and measured with AFM.

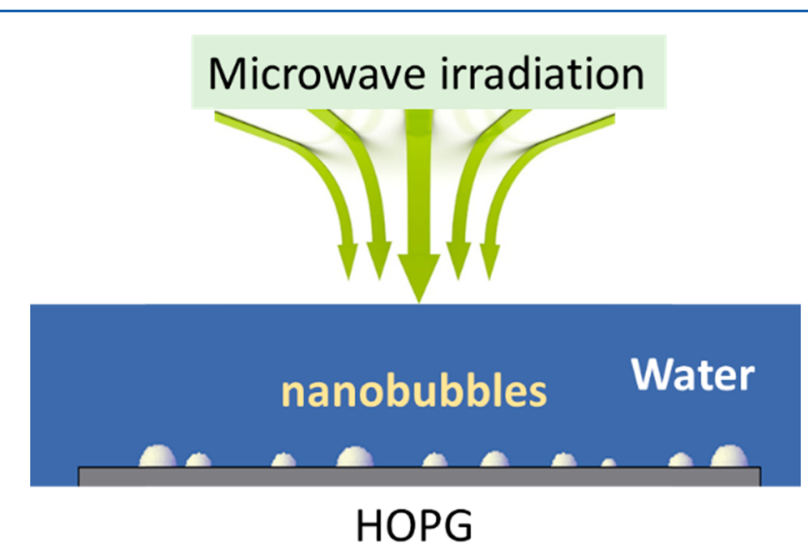

Figure 1. Schematic diagram of nanobubble generation via microwave.

2.3. Characterization of Nanobubbles. The AFM used in the experiment was a Multimode Nanoscope IIIa from Digital Instruments (Bruker AXS GmbH) equipped with a liquid cell and an O-ring that sealed the cell and the substrate to prevent liquid leakage during the measurement. During scanning, a vertical engage J scanner $(120 \times 120$ $\mu \mathrm{m}^{2}$ ) and silicon nitride cantilevers with a spring constant of around $0.32 \mathrm{~N} / \mathrm{m}$ were used. The probes were cleaned by immersing them in acetone and ethanol, respectively, and then rinsing with water. For imaging in fluid, the resonance frequency in tapping mode was from 7 to $12 \mathrm{kHz}$ and the amplitude set point was $80-90 \%$ of the free amplitude.

\section{RESULTS}

3.1. Generation of Interfacial Nanobubbles. The AFM image of the HOPG substrate (Figure 2a) showed that no nanobubbles were observed when the freshly cleaved HOPG substrate was simply immersed in water with $9.0 \mathrm{mg} / \mathrm{L}$ dissolved oxygen under an ambient environment. Nanobubbles were formed after $30 \mathrm{~s}$ of treatment by $400 \mathrm{~W}$ microwave irradiation (Figure 2b). The apparent diameter (lateral size) of nanobubbles was 200-600 nm. As shown in Figure 2c, oxygen nanobubbles still existed on the HOPG surface after $12 \mathrm{~h}$. Once nanobubbles formed on the hydrophobic surface, they remained stable even at high temperature and did not evolve into macroscopic bubbles. ${ }^{55}$ The mechanism behind such stability may be related to the strong pinning at the three-phase boundary, which needs to be confirmed by more quantitative experiments. In the degassed control system, the microwave treatment did not result in particle objects on the HOPG surface (Figure S1). A clear surface was revealed when the nanobubble area was scanned in contact mode (Figure 2d). The tip always contacted the substrate, and its force was strong enough to penetrate the soft nanobubbles. This result confirmed that microwave irradiation induced the formation of nanobubbles on the HOPG surface in water.

3.2. Effect of Irradiation Time and Microwave Working Power. Typical images of nanobubbles generated by microwave irradiation as a function of irradiation time were presented in Figure $3 \mathrm{a}-\mathrm{c}$. The irradiation power was set at 200 $\mathrm{W}$, and the initial oxygen concentration was $15.0 \mathrm{mg} / \mathrm{L}$. The density of nanobubbles on HOPG increased significantly with the increase in irradiation time. AFM images in contact mode proved that the generated bubblelike domains were indeed nanobubbles. The yield of oxygen nanobubbles increased about 

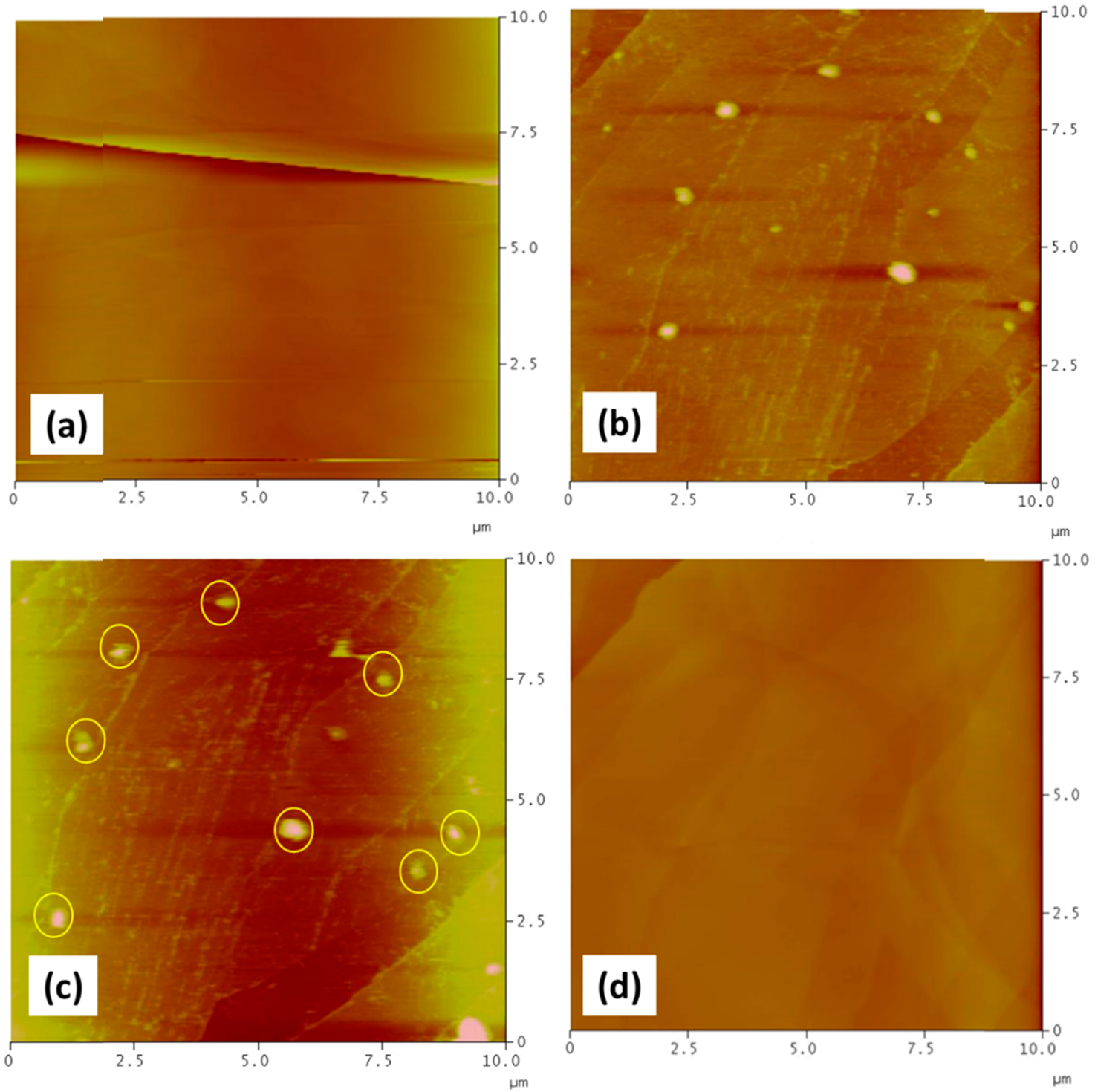

Figure 2. AFM images of the HOPG substrate and nanobubbles: (a) the HOPG surface in water without microwave treatment, (b) images of nanobubbles generated by microwave irradiation, (c) nanobubble images after $12 \mathrm{~h}$ of scanning, and (d) AFM contact mode of the same treatment sample. The scan size is $10 \mu \mathrm{m} \times 10 \mu \mathrm{m}$, and the height scale is $30 \mathrm{~nm}$.

10 -fold when the irradiation time increased from 60 to $120 \mathrm{~s}$ (Figure 4).

The effect of microwave power was also studied. All water samples with an initial oxygen concentration of $15.0 \mathrm{mg} / \mathrm{L}$ were treated for $30 \mathrm{~s}$ by microwave irradiation at different working powers. The yield of nanobubbles and the associated temperature profile are shown in Figure 5. Nanobubble formation is well correlated to the resulting temperature. An apparent improvement in nanobubble yield was found between 300 and $400 \mathrm{~W}$, where the resulting temperature was 34-52 ${ }^{\circ} \mathrm{C}$. The nanobubble density increased from 0.8 to $15 \mu \mathrm{m}^{-2}$ by improving the working power from 200 to $600 \mathrm{~W}$, suggesting that increasing work power improved the yield of nanobubbles.

3.3. Oxygen Concentration Effect. The gas concentration has been proven to be an important factor affecting the formation of nanobubbles. ${ }^{56}$ To study the oxygen concentration effect, we prepared water with different initial oxygen concentrations from 11.3 to $30.0 \mathrm{mg} / \mathrm{L}$. The initial temperature was $19{ }^{\circ} \mathrm{C}$. Samples were treated for $60 \mathrm{~s}$ with $300 \mathrm{~W}$ microwave irradiation, followed by AFM measurement. The resulting temperature was $45{ }^{\circ} \mathrm{C}$ after switching off the microwave irradiation. Typical images of nanobubbles as a function of oxygen concentration are shown in Figure 6. The yield of nanobubbles increased with increasing oxygen concentration (Figure 6e).

When HOPG was immersed in water oversaturated with oxygen with $30.0 \mathrm{mg} / \mathrm{L} \mathrm{DO}$ and no microwave treatment, no interfacial nanobubbles were observed (Figure 7).

\section{DISCUSSION}

\subsection{Generation of Interfacial Nanobubbles by Micro-} wave. It is well-known that water molecules are polar and have a high dielectric constant $\left(20^{\circ} \mathrm{C}, 80 \mathrm{~F} / \mathrm{m}\right)$ and dielectric loss factor and thus a strong ability to absorb microwave radiation. Graphite displays a strong microwave absorption ability and may yield "hot spots". ${ }^{50,51}$ Microwave treatment and temperature change in water are related (Table S1). The combination of a hot HOPG substrate and temperature change in water by microwave irradiation may be responsible for the formation of interfacial nanobubbles. Experimental results demonstrated that 

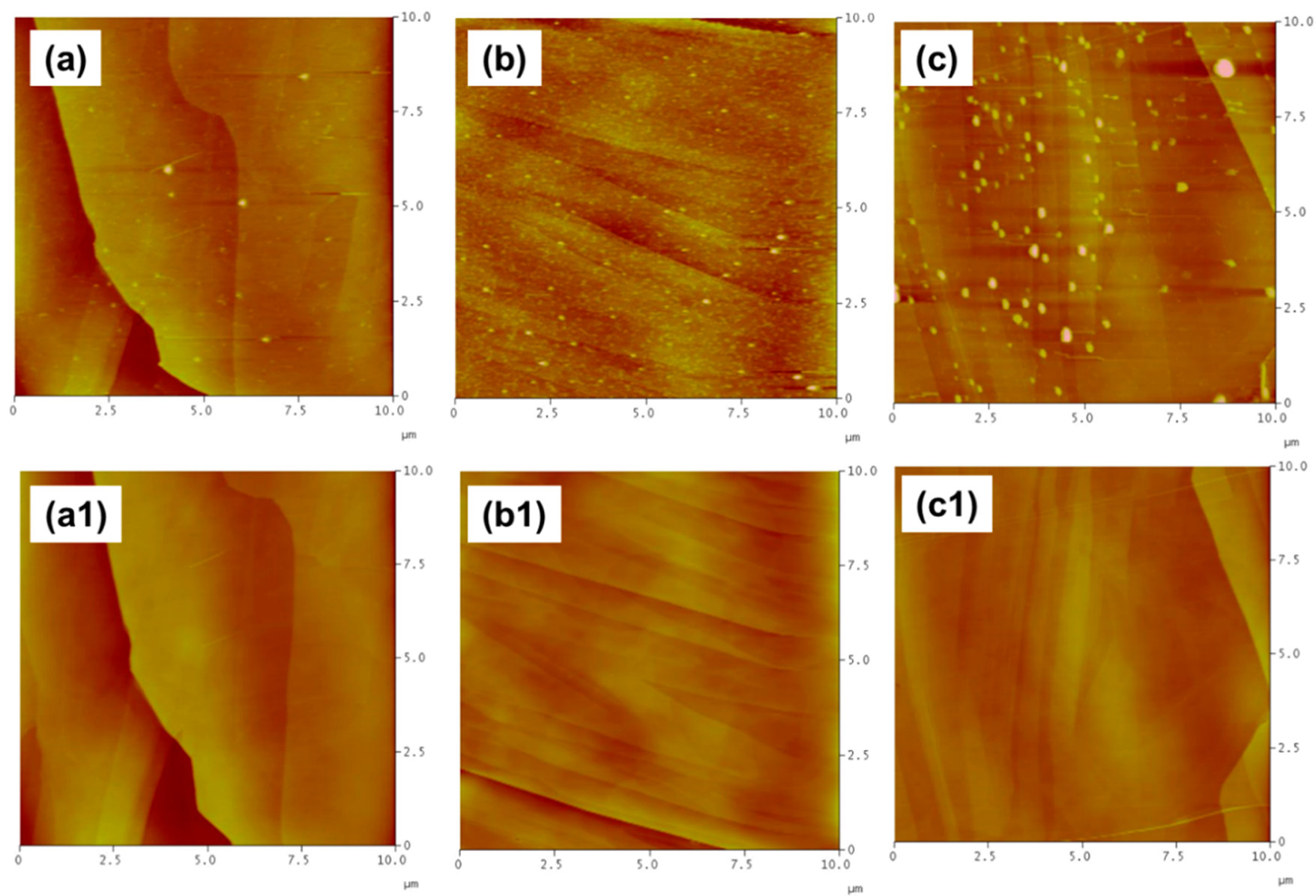

Figure 3. $(\mathrm{a}-\mathrm{c})$ AFM tapping mode height images of nanobubbles on the water-HOPG surface with different microwave irradiation times: (a) $60 \mathrm{~s}$, (b) $90 \mathrm{~s}$, and (c) $120 \mathrm{~s}$. (a1-c1) AFM images of these same samples in contact mode. The scan size is $10 \mu \mathrm{m} \times 10 \mu \mathrm{m}$, and the height scale is $30 \mathrm{~nm}$.

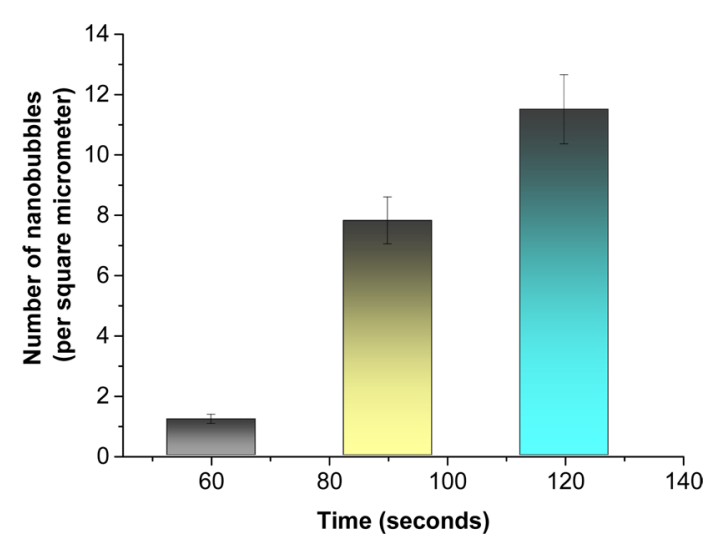

Figure 4. Effect of microwave irradiation time on the formation of nanobubbles.

the yield of nanobubbles was well associated with the irradiation time and working power. The yield of nanobubbles increased about 10 -fold when the irradiation time increased from 60 to $120 \mathrm{~s}$ by $200 \mathrm{~W}$ microwave treatment (Figure 4). The nanobubble density increased from 0.8 to $15 \mu \mathrm{m}^{-2}$ by improving the work power from 200 to $600 \mathrm{~W}$ (Figure 5). Microwave irradiation significantly enhanced nanobubble generation. By adjusting the microwave working power or irradiation time, it is possible to achieve the desired nanobubbles (number and size) quickly and conveniently.

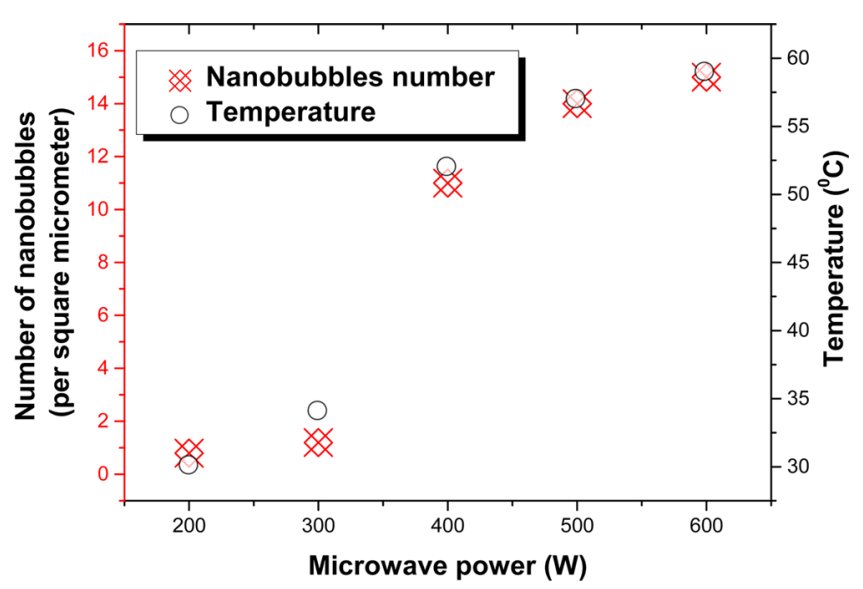

Figure 5. Effect of microwave power on the formation of nanobubbles.

Gas concentration played an important role in nanobubble formation. $^{56,57}$ Figure 8 shows the relationship between the oxygen concentration in water solution and the temperature variation caused by microwave irradiation. The higher the initial concentration of oxygen, the more oxygen released from the aqueous phase and thus a greater amount of induced nanobubble nucleation. The nanobubble yield was apparently increased from 1.2 to $13 \mu \mathrm{m}^{-2}$ when the initial concentration of oxygen was increased from 11.3 to $30 \mathrm{mg} / \mathrm{L}$ (Figure 6). Although the yield of oxygen nanobubbles can be largely manipulated by the oxygen concentration, it remains an 

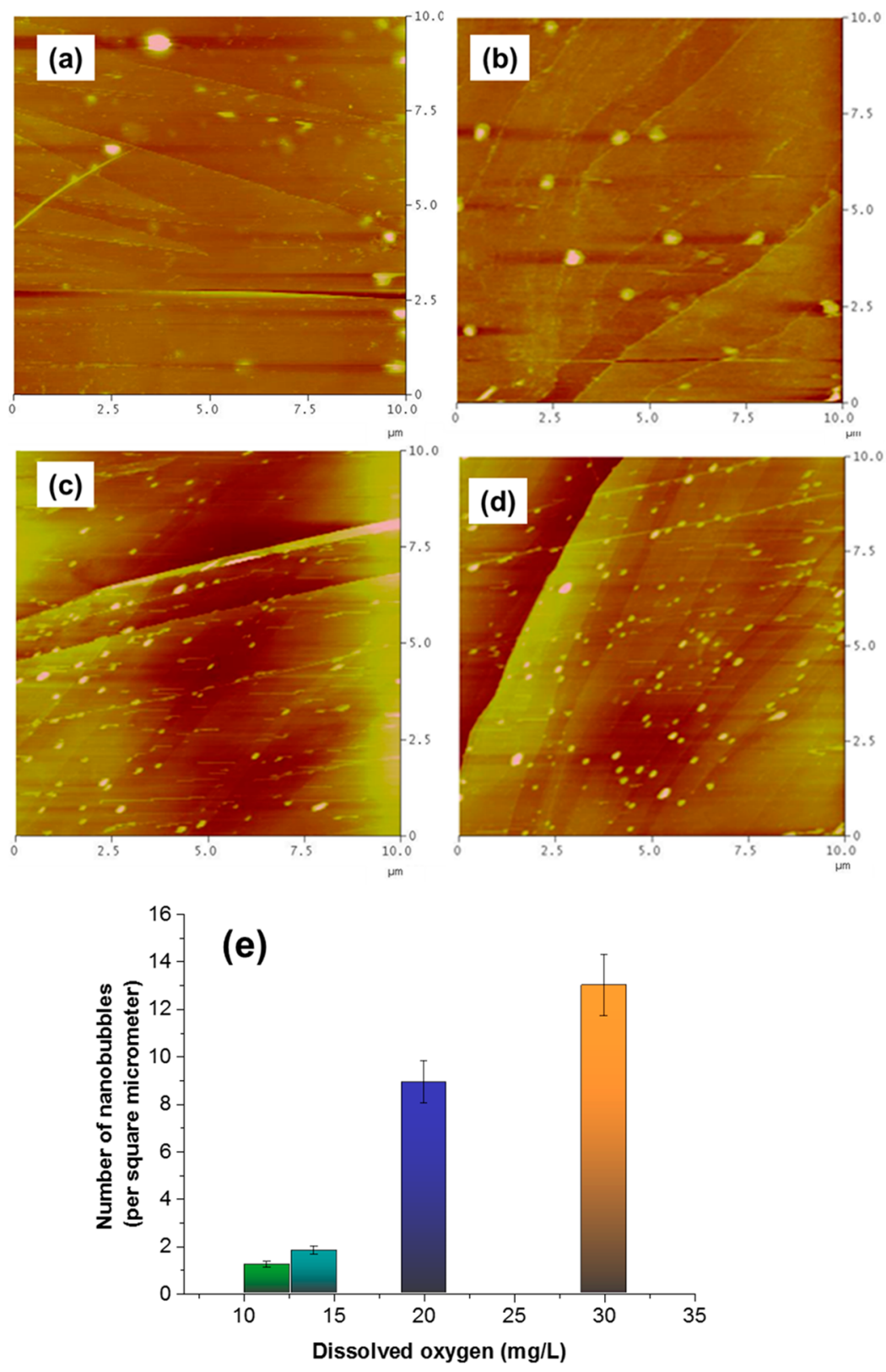

Figure 6. AFM height images of oxygen nanobubbles generated by microwave irradiation in water with different oxygen concentrations: (a) 11.3, (b) 13.9 , (c) 20.0 , and (d) $30.0 \mathrm{mg} / \mathrm{L}$. (e) Number of nanobubbles versus oxygen concentration. The scan size is $10 \mu \mathrm{m} \times 10 \mu \mathrm{m}$, and the height scale is $30 \mathrm{~nm}$.

interesting topic to study their stability under various water conditions such as the oxygen delivery effect in an aerobic environment.

\subsection{Possible Mechanism of Nanobubble Formation.}

In this study, nanobubbles were not observed by AFM when the freshly cleaved HOPG substrate was immersed in water with a rather high oxygen concentration $(9.0-30 \mathrm{mg} / \mathrm{L})$ in an ambient environment without microwave treatment (Figures $2 \mathrm{a}$ and 7). This agreed with the literature in that few nanobubbles can be detected simply by immersing a hydrophobic substrate in water. $^{20,57,58}$ Zhang et al. ${ }^{59}$ reported that interfacial nanobubbles were not observed when a smooth OTS-Si wafer was placed in a $\mathrm{CO}_{2}$-saturated water solution, and the interfacial bubbles are formed only through a fast solvent exchange treatment. It is widely accepted that the fast variation of gas solubility in water solution is key to inducing the nucleation of nanobubbles.

In this work, oxygen solubility in water was rapidly decreased with the temperature increase caused by the microwave treatment (Figure 8). The positive/negative direction of the electric field in microwave irradiation can change 2.45 billion times per second. ${ }^{50}$ The fast-changing electric fields of microwave irradiation lead to a rotation of the water molecule. The fast water shear flow and molecular friction can open the hydrogen bond between oxygen and the water molecule, resulting in the decrease in oxygen solubility in the aqueous solution. This is a physical process caused by the microwave nonthermal effect. ${ }^{54}$ In the meantime, severe temperature variations by the microwave thermal effect also helped to decrease the oxygen solubility. The nanobubble formation mechanism is described in the schematic diagram in Figure 9. 


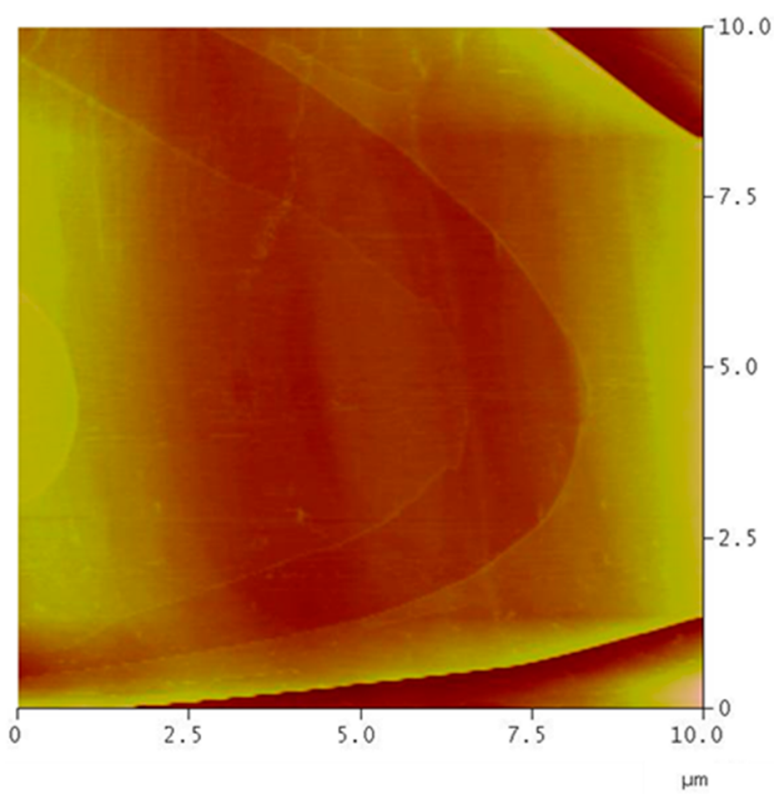

Figure 7. AFM image of the HOPG surface in water with $30.0 \mathrm{mg} / \mathrm{L}$ DO without microwave treatment.

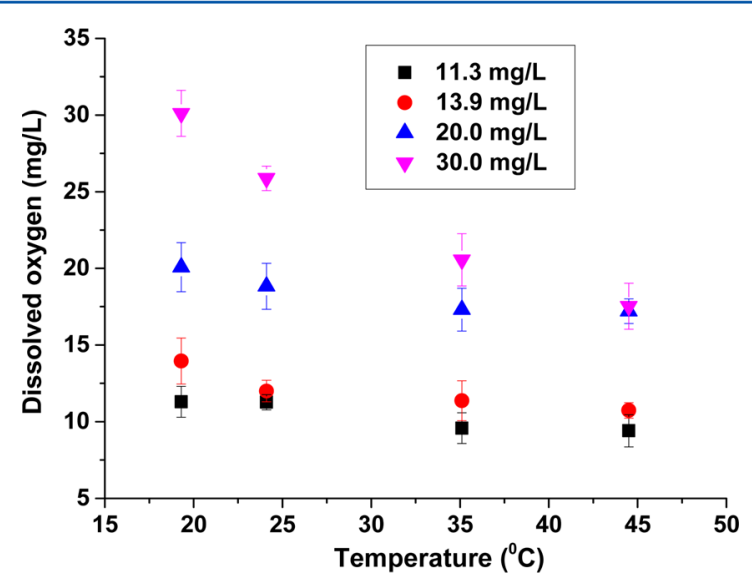

Figure 8. Oxygen concentration versus system temperature.

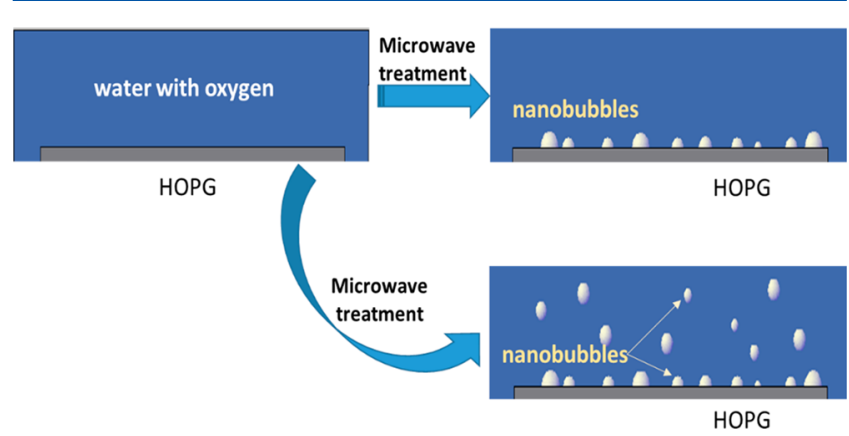

Figure 9. Possible mechanism of nanobubble formation.

One possible pathway is that interfacial nanobubbles could be formed by direct oxygen molecule nucleation and could accumulate on the HOPG surface as a nanoscale gas state. When irradiated with microwaves, HOPG could absorb microwave energy, resulting in a rapid heating of the surface. The violent release of heat by HOPG resulted in a rapid decrease in gas solubility in the surrounding domain, which contributes to nanobubble nucleation on the HOPG-water surface. Another possible pathway is that free oxygen nanobubbles could be formed in the bulk solution and then attached to the HOPG surface to form surface nanobubbles. ${ }^{16}$ Because of the strong microwave absorption ability, both the water and HOPG substrate temperatures could be well controlled by microwave irradiation, which is different from the nonselective temperature change method. ${ }^{35}$ In addition, the selective heating by microwave irradiation may be more energy efficient than conventional heating conduction through the whole medium.

4.3. Potential Impacts. This work confirmed that microwave irradiation is an effective way to prepare surface nanobubbles. To present direct evidence of nanobubbles, oxygen nanobubbles were generated and determined on a HOPG surface in this study. A recent study demonstrated that oxygen nanobubbles could be quantified at particle-water interfaces by scanning transmission soft X-ray microscopy. ${ }^{60}$ The controlled formation of nanobubbles via microwave may be valuable in preparing surface nanobubbles at various solid surfaces for practical applications, such as catalysis, hypoxia/ anoxia remediation, and templates for preparing nanoscale materials. It is interesting to study whether other types of nanobubbles can be produced by microwave treatment. It remains a challenge in the future to study the many mysteries related to nanobubbles such as the gas density inside nanobubbles and the stability on particle surfaces.

\section{CONCLUSIONS}

This work found that interfacial nanobubbles can be generated by microwave treatment. The yield of nanobubbles can be manipulated by adjusting the irradiation and gas concentration. Both thermal and nonthermal effects of microwave irradiation may be responsible for nanobubble nucleation as a result of the decrease in oxygen solubility in aqueous systems. The study provides a quick and convenient way to produce nanobubbles that may be useful for various applications.

\section{ASSOCIATED CONTENT}

\section{S Supporting Information}

The Supporting Information is available free of charge on the ACS Publications website at DOI: 10.1021/acs.langmuir.6b01620.

AFM image of HOPG after microwave treatment in the control system and temperature change with microwave power and interaction time (PDF)

\section{AUTHOR INFORMATION}

\section{Corresponding Author}

*E-mail: gpan@rcees.ac.cn.

\section{Notes}

The authors declare no competing financial interest.

\section{ACKNOWLEDGMENTS}

This work was supported by the Strategic Priority Research Program of the Chinese Academy of Sciences (XDA09030203), the National Natural Science Foundation of China (21407160), and the Science Promotion Program of Research Center for Eco-environmental Sciences, CAS (YSW2013B05). 


\section{REFERENCES}

(1) Parker, J. L.; Claesson, P. M.; Attard, P. Bubbles, cavities, and the long-ranged attraction between hydrophobic surfaces. J. Phys. Chem. 1994, 98 (34), 8468-8480.

(2) Ishida, N.; Inoue, T.; Miyahara, M.; Higashitani, K. Nano bubbles on a hydrophobic surface in water observed by tapping-mode atomic force microscopy. Langmuir 2000, 16 (16), 6377-6380.

(3) Lou, S. T.; Ouyang, Z. Q.; Zhang, Y.; Li, X. J.; Hu, J.; Li, M. Q.; Yang, F. J. Nanobubbles on solid surface imaged by atomic force microscopy. J. Vac. Sci. Technol., B: Microelectron. Process. Phenom. 2000, 18 (5), 2573-2575.

(4) Wang, Y.; Bhushan, B. Boundary slip and nanobubble study in micro/nanofluidics using atomic force microscopy. Soft Matter 2010, 6 (1), 29-66.

(5) Cavalli, R.; Bisazza, A.; Giustetto, P.; Civra, A.; Lembo, D.; Trotta, G.; Guiot, C.; Trotta, M. Preparation and characterization of dextran nanobubbles for oxygen delivery. Int. J. Pharm. 2009, 381 (2), $160-165$.

(6) Chang, S.; Si, T.; Zhang, S.; Merrick, M. A.; Cohn, D. E.; Xu, R. $\mathrm{X}$. Ultrasound mediated destruction of multifunctional microbubbles for image guided delivery of oxygen and drugs. Ultrason. Sonochem. 2016, 28, 31-38.

(7) Belova, V.; Gorin, D. A.; Shchukin, D. G.; Moehwald, H. Controlled effect of ultrasonic cavitation on hydrophobic/hydrophilic surfaces. ACS Appl. Mater. Interfaces 2011, 3 (2), 417-425.

(8) Ibrahimkutty, S.; Kim, J.; Cammarata, M.; Ewald, F.; Choi, J.; Ihee, H.; Plech, A. Ultrafast structural dynamics of the photocleavage of protein hybrid nanoparticles. ACS Nano 2011, 5 (5), 3788-3794.

(9) Brooks, M. Impossibubbles. New Sci. 2012, 215 (2872), 38-41.

(10) Pan, G.; Yang, B.; Wang, D.; Chen, H.; Tian, B.; Zhang, M.; Yuan, X.; Chen, J. In-lake algal bloom removal and submerged vegetation restoration using modified local soils. Ecol. Eng. 2011, 37 (2), 302-308.

(11) Pan, G.; Dai, L.; Li, L.; He, L.; Li, H.; Bi, L.; Gulati, R. D. Reducing the recruitment of sedimented algae and nutrient release into the overlying water using modified soil/sand flocculation-capping in eutrophic lakes. Environ. Sci. Technol. 2012, 46 (9), 5077-5084.

(12) Li, H.; Pan, G. Simultaneous removal of harmful algal blooms and microcystins using microorganism- and chitosan-modified local soil. Environ. Sci. Technol. 2015, 49 (10), 6249-6256.

(13) Craig, V. S. J. Very small bubbles at surfaces-the nanobubble puzzle. Soft Matter 2011, 7 (1), 40-48.

(14) Seddon, J. R. T.; Kooij, E. S.; Poelsema, B.; Zandvliet, H. J. W.; Lohse, D. Surface bubble nucleation stability. Phys. Rev. Lett. 2011, 106 (5), 056101.

(15) Dammer, S. M.; Lohse, D. Gas enrichment at liquid-wall interfaces. Phys. Rev. Lett. 2006, 96 (20), 206101.

(16) Pan, G.; Yang, B. Effect of surface hydrophobicity on the formation and stability of oxygen nanobubbles. ChemPhysChem 2012, 13 (8), 2205-2212.

(17) An, H.; Liu, G.; Atkin, R.; Craig, V. S. J. Surface nanobubbles in nonaqueous media: looking for nanobubbles in DMSO, formamide, propylene carbonate, ethylammonium nitrate, and propylammonium nitrate. ACS Nano 2015, 9 (7), 7596-7607.

(18) Peng, H.; Hampton, M. A.; Nguyen, A. V. Nanobubbles do not sit alone at the solid-iquid interface. Langmuir 2013, 29 (20), 61236130.

(19) Peng, H.; Birkett, G. R.; Nguyen, A. V. Origin of interfacial nanoscopic gaseous domains and formation of dense gas layer at hydrophobic solid-water interface. Langmuir 2013, 29 (49), 1526615274 .

(20) Zhang, X. H.; Maeda, N.; Craig, V. S. J. Physical properties of nanobubbles on hydrophobic surfaces in water and aqueous solutions. Langmuir 2006, 22 (11), 5025-5035.

(21) Yang, S.; Dammer, S. M.; Bremond, N.; Zandvliet, H. J. W.; Kooij, E. S.; Lohse, D. Characterization of nanobubbles on hydrophobic surfaces in water. Langmuir 2007, 23 (13), 7072-7077. (22) Weijs, J. H.; Lohse, D. Why surface nanobubbles live for hours. Phys. Rev. Lett. 2013, 110 (5), 054501.
(23) Lohse, D.; Zhang, X. Pinning and gas oversaturation imply stable single surface nanobubbles. Phys. Rev. E 2015, 91 (3), 031003.

(24) Borkent, B. M.; Dammer, S. M.; Schoenherr, H.; Vancso, G. J.; Lohse, D. Superstability of surface nanobubbles. Phys. Rev. Lett. 2007, 98 (20), 204502.

(25) Lauga, E.; Brenner, M. P. Dynamic mechanisms for apparent slip on hydrophobic surfaces. Phys. Rev. E 2004, 70 (2), 026311.

(26) Liu, G.; Craig, V. S. J. Improved cleaning of hydrophilic proteincoated surfaces using the combination of nanobubbles and SDS. ACS Appl. Mater. Interfaces 2009, 1 (2), 481-487.

(27) Liu, G.; Wu, Z.; Craig, V. S. J. Cleaning of protein-coated surfaces using nanobubbles: an investigation using a quartz crystal microbalance. J. Phys. Chem. C 2008, 112 (43), 16748-16753.

(28) Yang, S.; Duisterwinkel, A. Removal of nanoparticles from plain and patterned surfaces using nanobubbles. Langmuir 2011, 27 (18), 11430-11435.

(29) Calgaroto, S.; Wilberg, K. Q.; Rubio, J. On the nanobubbles interfacial properties and future applications in flotation. Miner. Eng. 2014, 60, 33-40.

(30) Plowman, B. J.; Jones, L. A.; Bhargava, S. K. Building with bubbles: the formation of high surface area honeycomb-like films via hydrogen bubble templated electrodeposition. Chem. Commun. 2015, 51 (21), 4331-4346.

(31) Yang, J. W.; Duan, J. M.; Fornasiero, D.; Ralston, J. Very small bubble formation at the solid-water interface. J. Phys. Chem. B 2003, 107 (25), 6139-6147.

(32) Guo, W.; Shan, H.; Guan, M.; Gao, L.; Liu, M.; Dong, Y. Investigation on nanobubbles on graphite substrate produced by the water- $\mathrm{NaCl}$ solution replacement. Surf. Sci. 2012, 606 (17-18), 14621466.

(33) Liu, M.; Zhao, W.; Wang, S.; Guo, W.; Tang, Y.; Dong, Y. Study on nanobubble generation: saline solution/water exchange method. ChemPhysChem 2013, 14 (11), 2589-2593.

(34) van Limbeek, M. A. J.; Seddon, J. R. T. Surface nanobubbles as a function of gas type. Langmuir 2011, 27 (14), 8694-8699.

(35) Lombard, J.; Biben, T.; Merabia, S. Nanobubbles around plasmonic nanoparticles: Thermodynamic analysis. Phys. Rev. E 2015, 91 (4), 043007.

(36) Zhang, L.; Zhang, Y.; Zhang, X.; Li, Z.; Shen, G.; Ye, M.; Fan, C.; Fang, H.; Hu, J. Electrochemically controlled formation and growth of hydrogen nanobubbles. Langmuir 2006, 22 (19), 81098113.

(37) Yang, S.; Tsai, P.; Kooij, E. S.; Prosperetti, A.; Zandvliet, H. J. W.; Lohse, D. Electrolytically generated nanobubbles on highly orientated pyrolytic graphite surfaces. Langmuir 2009, 25 (3), 14661474.

(38) Kikuchi, K.; Nagata, S.; Tanaka, Y.; Salhara, Y.; Ogumi, Z. Characteristics of hydrogen nanobubbles in solutions obtained with water electrolysis. J. Electroanal. Chem. 2007, 600 (2), 303-310.

(39) Kikuchi, K.; Tanaka, Y.; Saihara, Y.; Maeda, M.; Kawamura, M.; Ogumi, Z. Concentration of hydrogen nanobubbles in electrolyzed water. J. Colloid Interface Sci. 2006, 298 (2), 914-919.

(40) Kikuchi, K.; Tanaka, Y.; Saihara, Y.; Ogumi, Z. Study of hydrogen nanobubbles in solution in the vicinity of a platinum wire electrode using double-potential step chronoamperometry. Electrochim. Acta 2006, 52 (3), 904-913.

(41) Zhang, X. H.; Li, G.; Maeda, N.; Hu, J. Removal of induced nanobubbles from water/graphite interfaces by partial degassing. Langmuir 2006, 22 (22), 9238-9243.

(42) Hampton, M. A.; Donose, B. C.; Nguyen, A. V. Effect of alcohol-water exchange and surface scanning on nanobubbles and the attraction between hydrophobic surfaces. J. Colloid Interface Sci. 2008, 325 (1), 267-274.

(43) Lachaine, R.; Boulais, E.; Meunier, M. From thermo- to plasmamediated ultrafast laser-induced plasmonic nanobubbles. ACS Photonics 2014, 1 (4), 331-336.

(44) Baffou, G.; Polleux, J.; Rigneault, H.; Monneret, S. Superheating and micro-bubble generation around plasmonic nanoparticles under cw illumination. J. Phys. Chem. C 2014, 118 (9), 4890-4898. 
(45) Boulais, E.; Lachaine, R.; Hatef, A.; Meunier, M. Plasmonics for pulsed-laser cell nanosurgery: Fundamentals and applications. J. Photochem. Photobiol., C 2013, 17, 26-49.

(46) Kitz, M.; Preisser, S.; Wetterwald, A.; Jaeger, M.; Thalmann, G. N.; Frenz, M. Vapor bubble generation around gold nanoparticles and its application to damaging of cells. Biomed. Opt. Express 2011, 2 (2), 291-304.

(47) Chen, Q.; Luo, L.; White, H. S. Electrochemical generation of a hydrogen bubble at a recessed platinum nanopore electrode. Langmuir 2015, 31 (15), 4573-4581.

(48) Kikuchi, K.; Ioka, A.; Oku, T.; Tanaka, Y.; Saihara, Y.; Ogumi, Z. Concentration determination of oxygen nanobubbles in electrolyzed water. J. Colloid Interface Sci. 2009, 329 (2), 306-309.

(49) Chen, Q.; Wiedenroth, H. S.; German, S. R.; White, H. S. Electrochemical nucleation of stable $\mathrm{N}_{2}$ nanobubbles at Pt nanoelectrodes. J. Am. Chem. Soc. 2015, 137 (37), 12064-12069.

(50) Nuchter, M.; Ondruschka, B.; Bonrath, W.; Gum, A. Microwave assisted synthesis - a critical technology overview. Green Chem. 2004, 6 (3), 128-141.

(51) Nie, H.; Zhang, T.; Cui, M.; Lu, H.; Lovley, D. R.; Russell, T. P. Improved cathode for high efficient microbial-catalyzed reduction in microbial electrosynthesis cells. Phys. Chem. Chem. Phys. 2013, 15 (34), 14290-14294.

(52) Zheng, J.; Liu, H.; Wu, B.; Guo, Y.; Wu, T.; Yu, G.; Liu, Y.; Zhu, D. Production of high-quality carbon nanoscrolls with microwave spark assistance in liquid nitrogen. Adv. Mater. 2011, 23 (21), 24602463.

(53) Luo, Z.; Lu, Y.; Somers, L. A.; Johnson, A. T. C. High yield preparation of macroscopic graphene oxide membranes. J. Am. Chem. Soc. 2009, 131 (3), 898-899.

(54) Wroe, R.; Rowley, A. T. Evidence for a non-thermal microwave effect in the sintering of partially stabilized zirconia. J. Mater. Sci. 1996, 31 (8), 2019-2026.

(55) Xu, C.; Peng, S.; Qiao, G. G.; Gutowski, V.; Lohse, D.; Zhang, X. Nanobubble formation on a warmer substrate. Soft Matter 2014, 10 (39), 7857-7864.

(56) German, S. R.; Wu, X.; An, H.; Craig, V. S. J.; Mega, T. L.; Zhang, X. Interfacial nanobubbles are leaky: permeability of the gas/ water interface. ACS Nano 2014, 8 (6), 6193-6201.

(57) McKee, C. T.; Ducker, W. A. Refractive index of thin, aqueous films between hydrophobic surfaces studied using evanescent wave atomic force microscopy. Langmuir 2005, 21 (26), 12153-12159.

(58) Takata, Y.; Cho, J. H. J.; Law, B. M.; Aratono, M. Ellipsometric search for vapor layers at liquid-hydrophobic solid surfaces. Langmuir 2006, 22 (4), 1715-1721.

(59) Zhang, X. H.; Quinn, A.; Ducker, W. A. Nanobubbles at the interface between water and a hydrophobic solid. Langmuir 2008, 24 (9), 4756-4764.

(60) Pan, G.; He, G.; Zhang, M.; Zhou, Q.; Tyliszczak, T.; Tai, R.; Guo, J.; Bi, L.; Wang, L.; Zhang, H. Nanobubbles at hydrophilic particle water interfaces. Langmuir 2016, DOI: 10.1021/acs.langmuir.6b01483. 